\title{
Animal models of corneal endothelial dysfunction to facilitate development of novel therapies
}

\author{
Sangwan Park ${ }^{1}$, Brian C. Leonard ${ }^{1}$, Vijay Krishna Raghunathan ${ }^{2,3,4}$, Soohyun Kim ${ }^{1}$, Jennifer Y. Li ${ }^{5}$, \\ Mark J. Mannis ${ }^{5}$, Christopher J. Murphy ${ }^{1,5}$, Sara M. Thomasy ${ }^{1,5}$ \\ ${ }^{1}$ Department of Surgical and Radiological Sciences, School of Veterinary Medicine, University of California Davis, Davis, CA, USA; ${ }^{2}$ The Ocular \\ Surface Institute, College of Optometry, University of Houston, Houston, TX, USA; ${ }^{3}$ Department of Basic Sciences, University of Houston, \\ Houston, TX, USA; ${ }^{4}$ Department of Biomedical Engineering, Cullen College of Engineering, University of Houston, Houston, TX, USA; \\ ${ }^{5}$ Department of Ophthalmology \& Vision Science, School of Medicine, University of California Davis, Davis, CA, USA \\ Contributions: (I) Conception and design: S Park, SM Thomasy; (II) Administrative support: None; (III) Provision of study materials or patients: \\ None; (IV) Collection and assembly of data: S Park, S Kim; (V) Data analysis and interpretation: S Park, S Kim; (VI) Manuscript writing: All authors; \\ (VII) Final approval of manuscript: All authors. \\ Correspondence to: Sara M. Thomasy. Department of Surgical and Radiological Sciences, School of Veterinary Medicine, University of California, \\ Davis, Davis, CA 95616, USA. Email: smthomasy@ucdavis.edu.
}

\begin{abstract}
Progressive corneal endothelial disease eventually leads to corneal edema and vision loss due to the limited regenerative capacity of the corneal endothelium in vivo and is a major indication for corneal transplantation. Despite the relatively high success rate of corneal transplantation, there remains a pressing global clinical need to identify improved therapeutic strategies to address this debilitating condition. To evaluate the safety and efficacy of novel therapeutics, there is a growing demand for pre-clinical animal models of corneal endothelial dysfunction. In this review, experimentally induced, spontaneously occurring and genetically modified animal models of corneal endothelial dysfunction are described to assist researchers in making informed decisions regarding the selection of the most appropriate animal models to meet their research goals.
\end{abstract}

Keywords: Corneal endothelium; corneal endothelial disease; corneal endothelial injury; fuchs endothelial corneal dystrophy; pre-clinical animal models

Submitted May 31, 2020. Accepted for publication Sep 08, 2020.

doi: 10.21037/atm-20-4389

View this article at: https://dx.doi.org/10.21037/atm-20-4389

\section{Introduction}

Corneal endothelial cells (CECs) are critical for maintaining the relative corneal deturgescence through their pump and barrier functions. The CECs are slowly lost over time with aging and compensatory enlargement and migration of remaining adjacent CECs occurs to maintain their critical function despite decreasing cell density $(1,2)$. Human CECs (as well as those of other species) have limited proliferative capabilities. As a result, extensive cell loss from injury, toxic insult or diseases can rapidly exceed the functional reserve of the corneal endothelium $(1,3)$ and lead to irreversible endothelial dysfunction which manifests clinically as corneal edema, bullous keratopathy and decreased vision.

Since the early 1900's, penetrating keratoplasty (PK) had been considered the gold standard therapy for severe corneal edema $(4,5)$. Over the past decade, posterior lamellar keratoplasty has replaced full thickness PK as the surgical procedure of choice for endothelial dysfunction (6). A lack of donor tissue worldwide, however, has stimulated research to improve current surgical techniques with the help of cell culture and tissue engineering for advanced endothelial disease $(3,4)$. Stimulating research into the promotion of CEC regeneration were reports of endothelial regeneration after Descemet's Stripping Only (DSO) procedures and spontaneous corneal clearance even with 
graft detachment after endothelial keratoplasty (EK) (6-10). The proliferative potential human CECs was reported in vitro and ex vivo in the early 1980s (11-13) and led to the investigation of new therapies aimed at accelerating proliferation of remaining CECs in vivo for treating early stages of endothelial dysfunction (3).

Cell-based therapies with ex vivo cell expansion for corneal endothelial dysfunction represent a promising approach for reducing the current dependency on fresh corneal donors and may potentially resolve a global shortage of donor corneas. In addition, there is ample evidence suggesting stem-like corneal endothelial progenitor cells in the periphery of the endothelium at the posterior corneal limbus. Stem cell markers (nestin, telomerase, Oct-3/4, and Wnt-1) and endothelial-specific differentiation markers (Pax-6 and Sox-2) were identified particularly in the wounded corneas (14) and the specific niches for endothelial progenitor cells were recently characterized $(15,16)$. Endothelial progenitor cells would be promising source of cell-based therapy (17). Approaches for delivery of cultured CECs onto the posterior cornea include injecting the cells into the anterior chamber in the form of a cell suspension or transplantation of a bioengineered CEC sheet. Despite the improvement in cell culture protocols, concerns remain regarding the maintenance of endothelial phenotype upon stimulation of mitosis. Several pharmacological agents have been investigated to address these concerns.

Rho-associated, coiled-coil-containing protein kinase (ROCK) inhibitors are the best investigated compounds to promote CEC regeneration. ROCK inhibitors stimulate CEC proliferation and migration as well as suppress apoptosis in vitro (18). They are critical to the success of cell injection therapy by promoting cell adhesion onto the posterior cornea in pre-clinical animal models and human clinical trial (19-23). Furthermore, ROCK inhibitors have the potential to enhance CEC wound healing when used as a topical ophthalmic medication (22,24-27).

Another agent that has been studied to enhance CEC proliferation is fibroblast growth factor-2 (FGF-2). However, FGF-2 accelerates endothelial-to-mesenchymal transition (EnMT) of CECs thereby limiting its utility with cultured CECs in tissue engineering $(2,4,28)$. Similarly, nicotinamide and its related derivatives were also shown to be promising for enhancing CEC wound healing by stimulating CEC proliferation. However, unlike FGF-2, nicotinamide and its derivatives also help inhibit EnMT in mice and rabbits (29-31).

In this new era of cell and tissue engineering-based novel therapeutics, and with the development of agents that promote proliferation of CECs in situ, there is a growing interest in and demand for pre-clinical animal models of corneal endothelial dysfunction to evaluate safety and efficacy of new treatments. Historically, various methods of direct injury of normal CECs have been attempted to investigate CEC regeneration physiology. These studies have expanded our understanding of the pathogenesis of endothelial diseases, and have been employed in establishing the safety and efficacy of novel therapeutics in normal experimental animals. A small array of genetically-based corneal endothelial diseases (both spontaneous and induced) have been reported, predominantly in mice. In addition, there are non-traumatic inducible animal models as well as animals that develop spontaneous corneal endothelial dysfunction including client-owned veterinary patients. The introduction of advanced ocular imaging in veterinary medicine enables clinicians and researchers to monitor progression of spontaneously developed ocular diseases in vivo.

Below we review: (I) experimental methods to induce CEC injury in animal models, (II) genetically modified animal models and (III) spontaneously occurring corneal endothelial dysfunction identified in lab animals and veterinary patients to inform investigators in selecting the most appropriate animal model for their research goals.

\section{Variations in corneal endothelial regeneration}

Although ample evidence exists that human CECs can proliferate under certain conditions (11-13,32), they are considered post-mitotic in vivo, such that mitosis does not occur at a level sufficient to replace damaged or lost CECs (1). It is thought that CECs are arrested in nonmitotic G1 phase because densely packed cells exhibit strong contact inhibition through the activity of cyclin-dependent kinase inhibitors such as p27kip1 (33). Inhibitory growth factors such as transforming growth factor- $\beta$ (TGF- $\beta$ ) in the aqueous humor may also contribute to maintain the corneal endothelium in a non-replicative state when cellcell contact is lost $(2,33)$. Furthermore, chronic oxidative stress from a combination of high intrinsic metabolic rate and environmental ultraviolet (UV) light exposure is thought to play a role in the limited proliferative capacity of CECs (2,34).

With damage, corneal endothelial wound healing occurs predominantly by enlargement and migration of the adjacent cells at the wound margin. This type of wound 


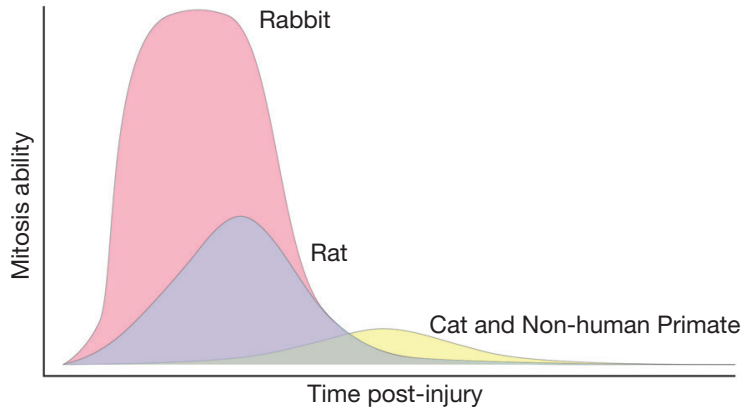

Figure 1 Corneal endothelial regenerative capacity varies by species. Following corneal endothelial injury, rabbits demonstrate rapid and robust mitosis consistent with their high regenerative capacity. The corneal endothelial cells of rodents also demonstrate some mitotic capacity although it is slower than in rabbits. By contrast, cats and non-human primates demonstrate little mitotic ability consistent with that of humans.

healing process is universal in all species, regardless of the nature of corneal endothelial injury (1,35). CEC migration occurs at a rate of $\sim 0.5-1 \mathrm{~mm} /$ day (36) which is followed concomitantly by cell proliferation $12-24 \mathrm{~h}$ after endothelial injury, particularly in rabbits (37). However, there are wide species-specific variations in the mitotic ability of CECs, impacting the speed and capacity of endothelial regeneration (Figure 1).

Rabbit CECs are known for tremendous regenerative capacity from extensive mitosis $(38,39)$. Autoradiography of the uptake of tritiated thymidine $\left({ }^{3} \mathrm{H}-\mathrm{Tdr}\right)$ into nuclear DNA is a marker of mitotic cell division in experimental animals. At 24 hours post-cryoinjury, nearly $100 \%$ of cells near the wound margin showed uptake of ${ }^{3} \mathrm{H}-\mathrm{Tdr}$ in rabbits and maximal incorporation was observed 24-48 h post-injury, while little uptake was observed at $48 \mathrm{~h}$ postinjury in cats $(40,41)$. In rats following both cryoinjury and mechanical scraping injury, ${ }^{3} \mathrm{H}-\mathrm{Tdr}$ uptake initially occurred at $36 \mathrm{~h}$ and peaked at $48 \mathrm{~h}$ with $45 \%$ of cells showing uptake (39). Non-human primate (NHP) CECs showed uptake of ${ }^{3} \mathrm{H}-\mathrm{Tdr}$ in $<20 \%$ of cells at $48-96 \mathrm{~h}$ postcryoinjury (42). In a canine study, moderate incorporation of ${ }^{3} \mathrm{H}$-Tdr into CECs was observed at 3-7 days postcryoinjury (43). Following cryoinjury of $90 \%$ of CECs, corneal thickness returned to normal at 4-6 weeks in dogs (43) but did not return to normal until 1 month in cats (40) suggesting that CEC regenerative capacity in dogs is superior to that of cats. In aggregate, these data suggest that CECs of cats and NHPs more closely approximate that of humans. This suggests that these species may be more suitable for studies of corneal endothelial regeneration $(38,40,44,45)$.

In addition to wide species variability in corneal endothelial wound responses, there is also evidence of differential CEC regeneration with ROCK inhibitors. While Y-27632, a well-known ROCK inhibitor, was reported to enhance corneal endothelial regeneration in rabbits, primates, and dogs in vivo (19-22,46), injection of cultured CECs supplemented with Y-27632 failed to regenerate corneal endothelium in cats (47). Species difference as well as differences in the capacity and methods used for inducing CEC injury and culturing CECs could be responsible for this incongruous result in cats.

Although cats and NHPs have a limited CEC regenerative capacity similar to that of humans, rabbits are used most frequently for in vivo research of CEC therapy due to their large eye, relatively lower costs and ethical considerations (38). To increase the predictive value of preclinical findings in rabbits to human applications, the use of older rabbits at a minimum age of 9-12 months old could be a viable option since they demonstrated lower CEC density and increased polymegathism when compared with younger rabbits $(48,49)$. Additionally, mitotic activity was significantly decreased with increasing age as 18 -monthold rabbits did not show mitotic activity $72 \mathrm{~h}$ after cryoinjury (50), supporting delayed endothelial wound healing in older rabbits (Figure 2). It is thus important for researchers to consider these intrinsic species differences to best meet the intent of the studies being undertaken.

\section{Methods for inducing corneal endothelial injury}

\section{Transcorneal cryoinjury}

Since the first report by Maumenee et al. in 1948, transcorneal cryoinjury has been a popular method to induce CEC dysfunction (51-53). Despite its simplicity of application and relatively non-invasive nature, the freeze-induced CEC wound and the resultant wound healing behavior varies depending on the temperature, size and duration of the probe application, requiring careful standardization (Table 1) (52,57). Generally, liquid nitrogen is used to cool the probe to $-80-196^{\circ} \mathrm{C}$. Given that the temperature of the probe continuously rises during the first 3-5 seconds after application (57), the probe should be cooled immediately before each use. If the temperature and duration are correct, the application 
A

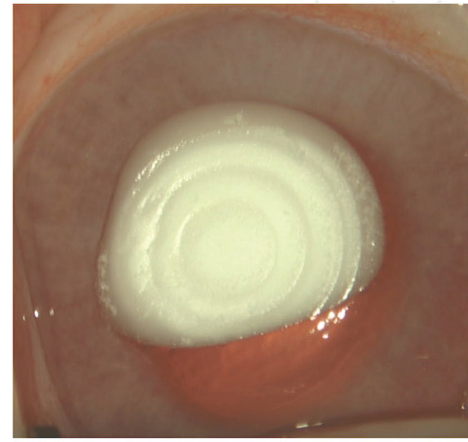

Slit lamp biomicroscopy

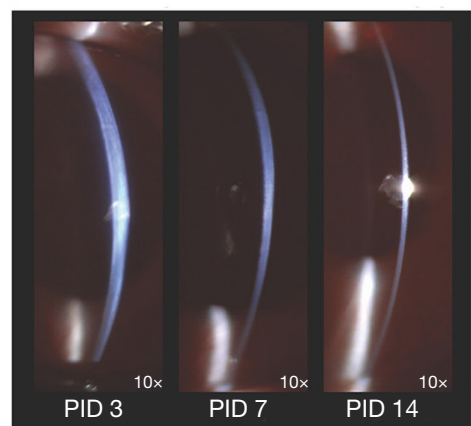

B
FD-OCT

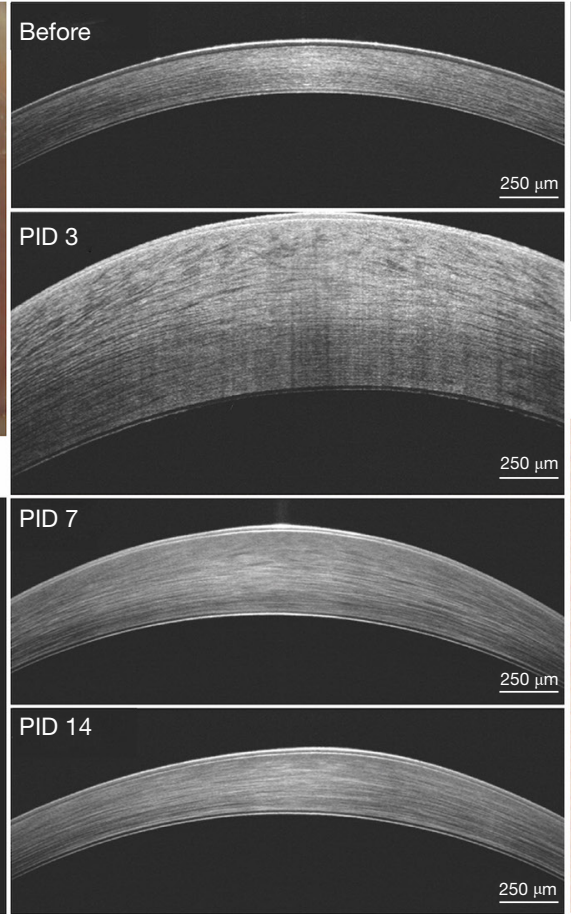

IVCM

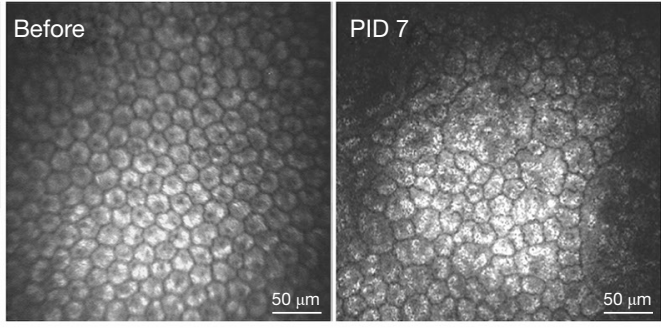

Alizarin red stain on PID 14

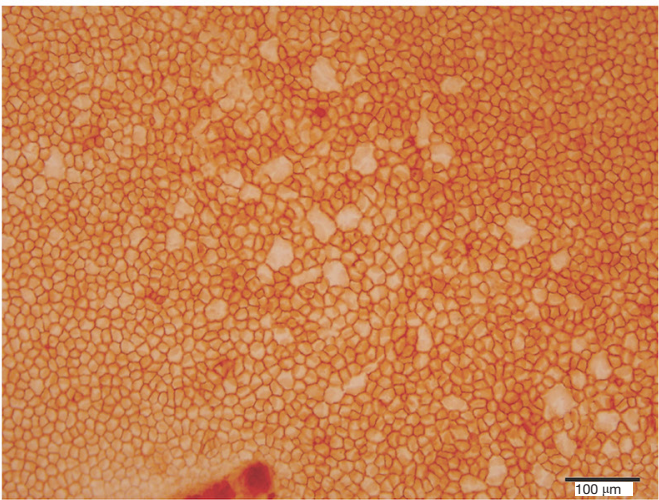

Central corneal thickness (CCT)

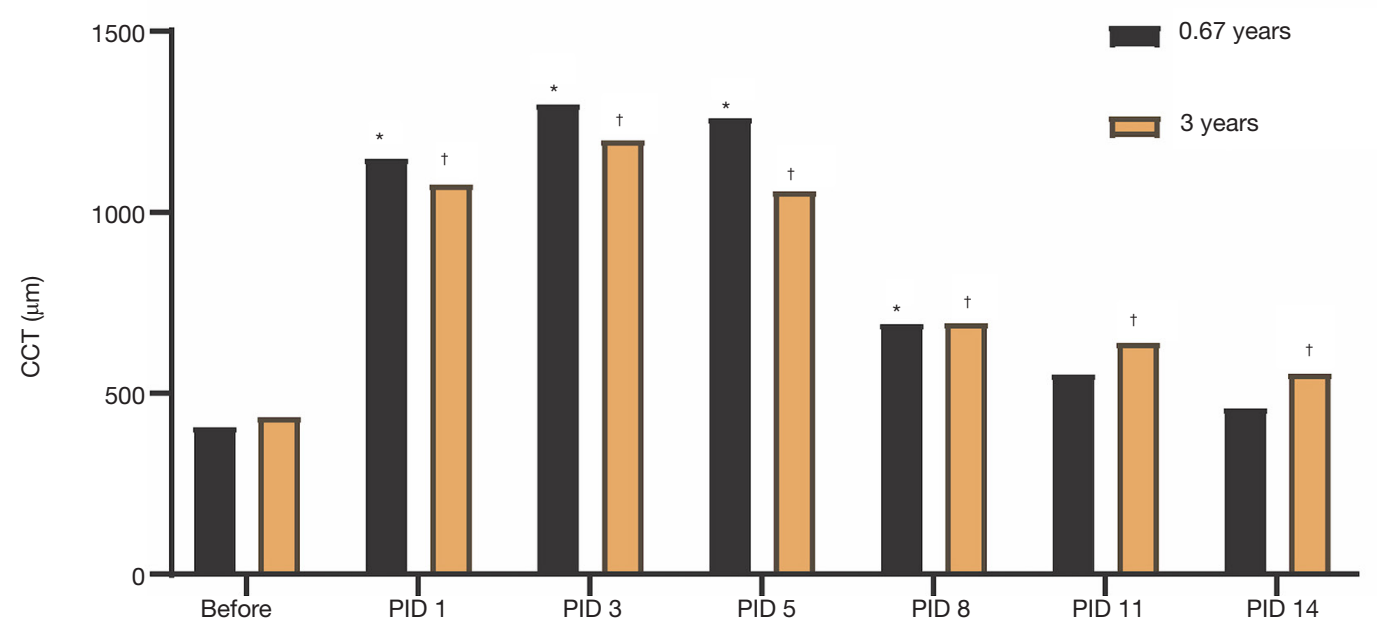

Figure 2 Transcorneal cryoinjury in rabbits. (A) An 8-mm diameter cryoprobe cooled to an approximate temperature of $-196{ }^{\circ} \mathrm{C}$ was applied to the cornea for 15 seconds and the cornea was allowed to thaw spontaneously. Following cryoinjury, multimodal advanced ocular imaging including slit lamp biomicroscopy, FD-OCT and IVCM were utilized to monitor clinical progression as well as endothelial wound healing. These imaging modalities demonstrated maximal edema and thickening of the central cornea on PID 3 with return to normal corneal thickness and transparency on PID 14. After euthanasia at the completion of the study, alizarin red staining was performed in corneal wholemounts to evaluate endothelial cell morphology and density. (B) Cryoinjury was performed in two different age groups of rabbits and CCT was evaluated for 14 days post-injury. CCT gradually decreased and returned to normal on PID 11 in 0.67 -year-old rabbits, but CCT still remained elevated at $>500 \mu \mathrm{m}$ on PID 14 in 3-year-old rabbits. *P values represent comparison of CCT before and after cryoinjury in 0.67-year-old rabbits; ${ }^{\dagger}, \mathrm{P}$ values represent comparison of CCT before and after cryoinjury in 3-year-old rabbits; paired t-test. CCT, central corneal thickness; FD-OCT, Fourier-domain optical coherence tomography; IVCM, in vivo confocal microscopy; PID, post-injury day. 


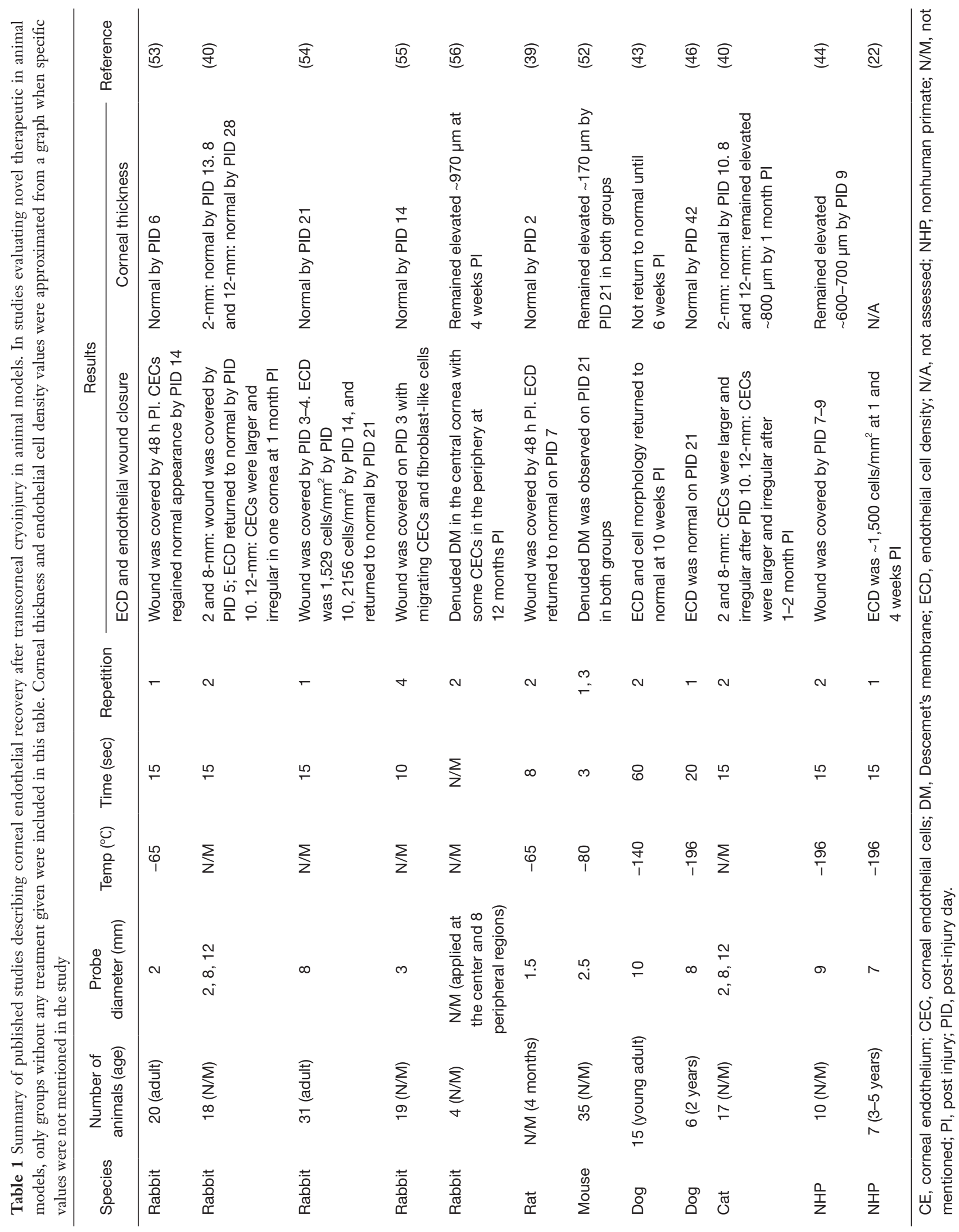


A

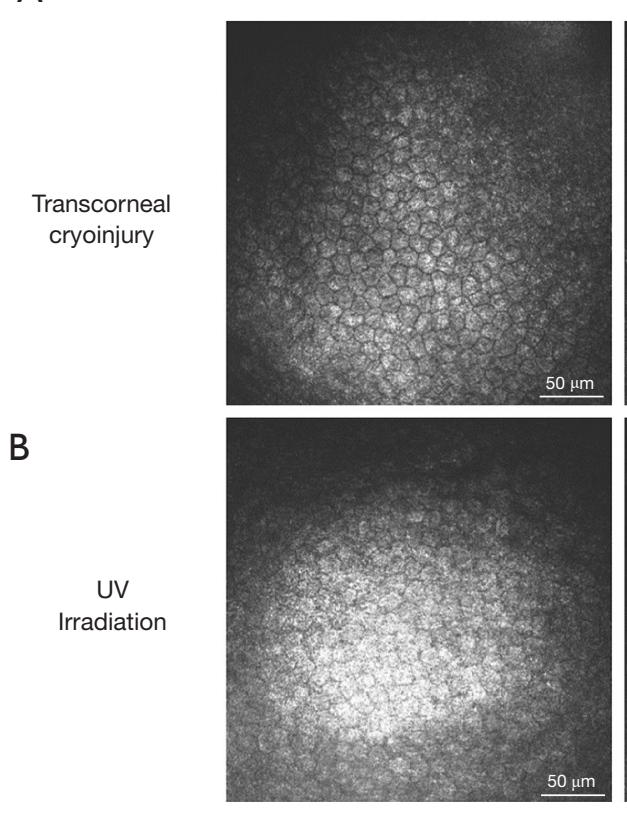

PID 1
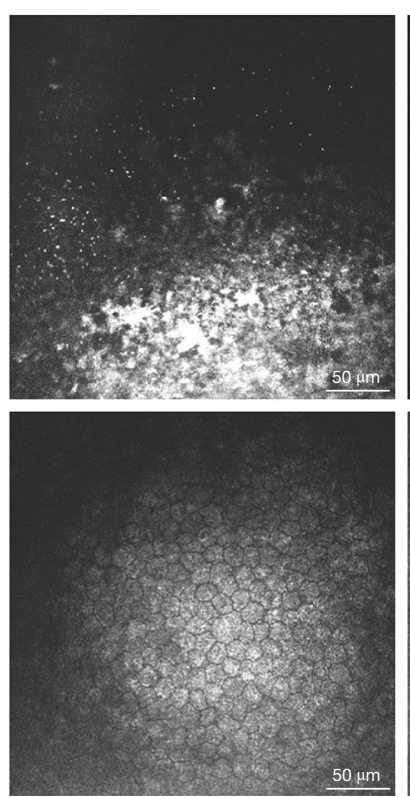

PID 3
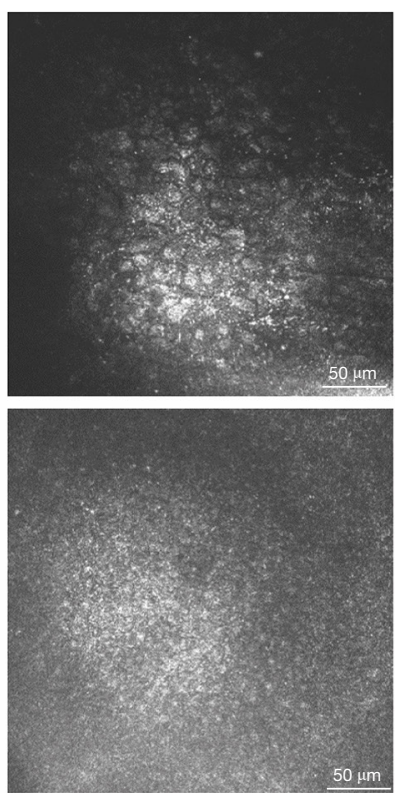

Figure 3 Corneal endothelial wounds and healing vary depending on the inciting cause. (A) A 2-mm diameter cryoprobe of approximately $-196{ }^{\circ} \mathrm{C}$ was applied to the cornea for 3 seconds in 6-month old mice. Immediately after cryoinjury, CECs were destroyed and inflammatory debris were observed on PID 1. On PID 3, regenerating CECs were observed migrating into the wound area. (B) A $302 \mathrm{~nm}$ UV-B with irradiance of 5,900 $\mathrm{mW} / \mathrm{cm} 2$ was exposed to the cornea of 6-month-old mice. In contrast to cryoinjury, UV irradiation resulted in mild cellular changes on PID 1 and a bare Descemet's membrane with little cellular debris on PID 3. CEC, corneal endothelial cell; PID, postinjury day.

should result in the formation of an ice ball in the anterior chamber $(24,40,44,57)$.

Compared to other methods of injury, cryoinjury induces corneal epithelial disruption and requires monitoring with corneal fluorescein staining and topical antibiotic application until reepithelialization $(40,44)$. Corneal epithelial defects are usually completely healed by $5-7$ days post-injury (57). Monitoring corneal thickness has been utilized as an indirect indicator of CEC regeneration (44), and the contribution of epithelial disruption to development of corneal edema should be considered in the early phase of healing period (54). The corneal endothelium is more sensitive to freezing than the epithelium and stroma $(57,58)$, thus neither corneal vascularization nor secondary infection typically occurs and inflammatory cells do not usually infiltrate the cornea under standardized conditions $(51,57)$.

Meanwhile, varying degrees of anterior uveitis commonly follows transcorneal cryoinjury (Figure $3 A$ ). Fibrin can develop in the anterior chamber immediately after cryoinjury and typically resolves at $\sim 7$ days post-injury in rabbits $(37,57)$. In rodents with small anterior chamber volumes, cryoinjury results in marked uveitis $(52,59)$. Fibrin clots adherent to the endothelium are frequently observed and peripheral anterior synechiae and cataract can also occur in rodents $(39,52)$; hyphema develops when excessive damage occurs in mice (52).

Retrocorneal fibrous membranes (RCFM) between Descemet's membrane (DM) and regenerating CECs can develop following cryoinjury, which does not occur with mechanical scrape injury $(37,40,44,56,60)$. RCFM formation is likely due to EnMT whereby regenerating endothelial cells transform into fibroblast-like cells which lose normal junctional complexes, begin expressing $\alpha$-smooth muscle actin ( $\alpha$-SMA), and produce abnormal fibrillar extracellular matrix (ECM) post-cryoinjury $(37,55,61-63)$. Inflammation, particularly fibrin formation, likely triggers $\operatorname{EnMT}(55,60)$. Indeed, cryoinjury has been a standard in vivo model to study the cellular biology of EnMT (61) with signaling pathways involving FGF-2, TGF- $\beta$, and IL- $1 \beta$ important in EnMT induction $(28,63)$. In order to prevent fibroblastic transformation of CECs, several measures such as inhibition of TGF- $\beta$ signaling and decreasing p27kip1 expression by 
knockdown of Connexin 43 have been developed $(2,4,28)$. Notably, EnMT-induced CECs cultured with TGF- $\beta$ and basic FGF supplemented medium, transplanted to bare DM induced longer-standing bullous keratopathy in rabbits than standard acute injury animal models (64).

Given the role of inflammation in determining the path of CEC wound healing, inflammation should be carefully monitored post-injury in a consistent manner based upon semiquantitative scoring criteria (65). Monitoring CEC wound healing behavior such as corneal thickness and endothelial cell density can benefit from multimodal corneal imaging including optical coherence tomography (OCT) and in vivo confocal microscopy (IVCM) (Figure 2).

Transcorneal cryoinjury has been used commonly in preclinical studies evaluating novel therapeutics in rodents $(66,67)$, rabbits $(24,56,68,69)$, dogs $(46)$, and NHPs $(22)$. Cryoinjury induces desquamation of CECs into the anterior chamber $(1,36,56)$, which releases contact inhibition of CECs and promotes cell proliferation. In a small case series of human patients with Fuchs endothelial corneal dystrophy (FECD), cryoinjury followed by topical treatment with a ROCK inhibitor showed clinical improvement by stimulating cell proliferation of the remaining nonaffected CECs (26).

\section{Mechanical injury}

Mechanical injury refers to the introduction of an instrument into the anterior chamber to remove the endothelium by scraping. Multiple techniques have been used to scrape CECs while leaving DM intact including a blunt spatula/needle or custom-made instruments to create linear or round wounds denuded of CECs (39,41,45,55,70-76). Another technique involves implantation of a magnetic foreign body into the anterior chamber and manipulating it with a magnet externally to abrade the endothelium $(77,78)$.

One of the important caveats of the mechanical debridement technique is the possibility of damaging DM. It has been shown that the integrity of DM impacts CEC regeneration and even small DM injuries delay healing of CECs in rabbits and humans $(7,74)$. The edges of the injured DM retract and curl toward the stroma creating a physical barrier to CEC migration into the wound $(1,74)$. Furthermore, damage of DM leading to exposure of the stroma results in the formation of RCFM possibly derived from activated keratocytes $(1,35,74,79)$ that could alter the microenvironment of CECs and lead to differential wound healing behavior of CECs across intact versus injured DM.

Chen and colleagues demonstrated the two diverging paths of CEC regeneration by comparing CEC scraping and DM stripping in rabbits (79). After CEC scraping injury with an intact DM, adjacent CECs undergo EnMT and demonstrate $\alpha$-SMA expression to migrate to the wound bed, then regain an endothelial phenotype after wound closure. With DM stripping and exposure of corneal stroma, migration of CECs was limited with RCFM development. Additionally, regenerated cells in the wound bed were not of CEC origin and exhibited $\alpha$-SMA expression even after wound closure. The origin of the regenerated cells has yet to be identified, but it is assumed that keratocytes in corneal stroma might have been activated and transformed into myofibroblasts subsequent to exposure to TGF- $\beta$ in aqueous humor. Keratocytes and CECs both derive from neural crest tissue developmentally. Keratocytes may be able to transdifferentiate into CEC-like cells and partially acquire an endothelial phenotype, thereby contributing to the resolution of corneal edema during the wound healing $(2,79)$.

In a feline study utilizing a CEC scraping injury model with an intact DM, a fibrotic healing response was observed with RCFM in a group receiving an $18-\mathrm{mm}$ diameter injury, while the group receiving a $7-\mathrm{mm}$ diameter injury healed normally (47). Therefore, both the size and nature of the injury may impact the activation of EnMT signaling pathways.

DM stripping is a key step in EK techniques particularly in FECD $(8,80)$. The accumulated experience and success of EK has encouraged research into the use of cultured CEC transplantation either alone or on a thin carrier (cultured CEC sheet). Pre-clinical animal models of DM stripping have been utilized to evaluate various biological and synthetic carrier materials seeded with cultivated CECs to promote adhesion of the cell sheets to the posterior corneal surface and to reduce the possibility of regeneration from the remaining host CECs (81-86). Meanwhile, DM stripping alone is a viable option for early stage FECD patients whose DM shows abnormal excrescences (guttae) acting as a physical barrier and interfering with cell migration (87). Okumura and colleagues demonstrated that DM stripping in the optical zone in combination with cultivated CEC injection is feasible for FECD patients to further improve visual quality using a rabbit model (88).

Table 2 summarizes structural and functional behavior of CEC wound healing following CEC scraping and/ or DM stripping in several published studies. Note that 
Table 2 Summary of published studies describing corneal endothelial recovery after mechanical injury in animal models. In the studies of evaluating novel therapeutic in animal models, only groups without any treatment given were included in this table. Corneal thickness and endothelial cell density values were approximated from a graph when specific values were not mentioned in the study

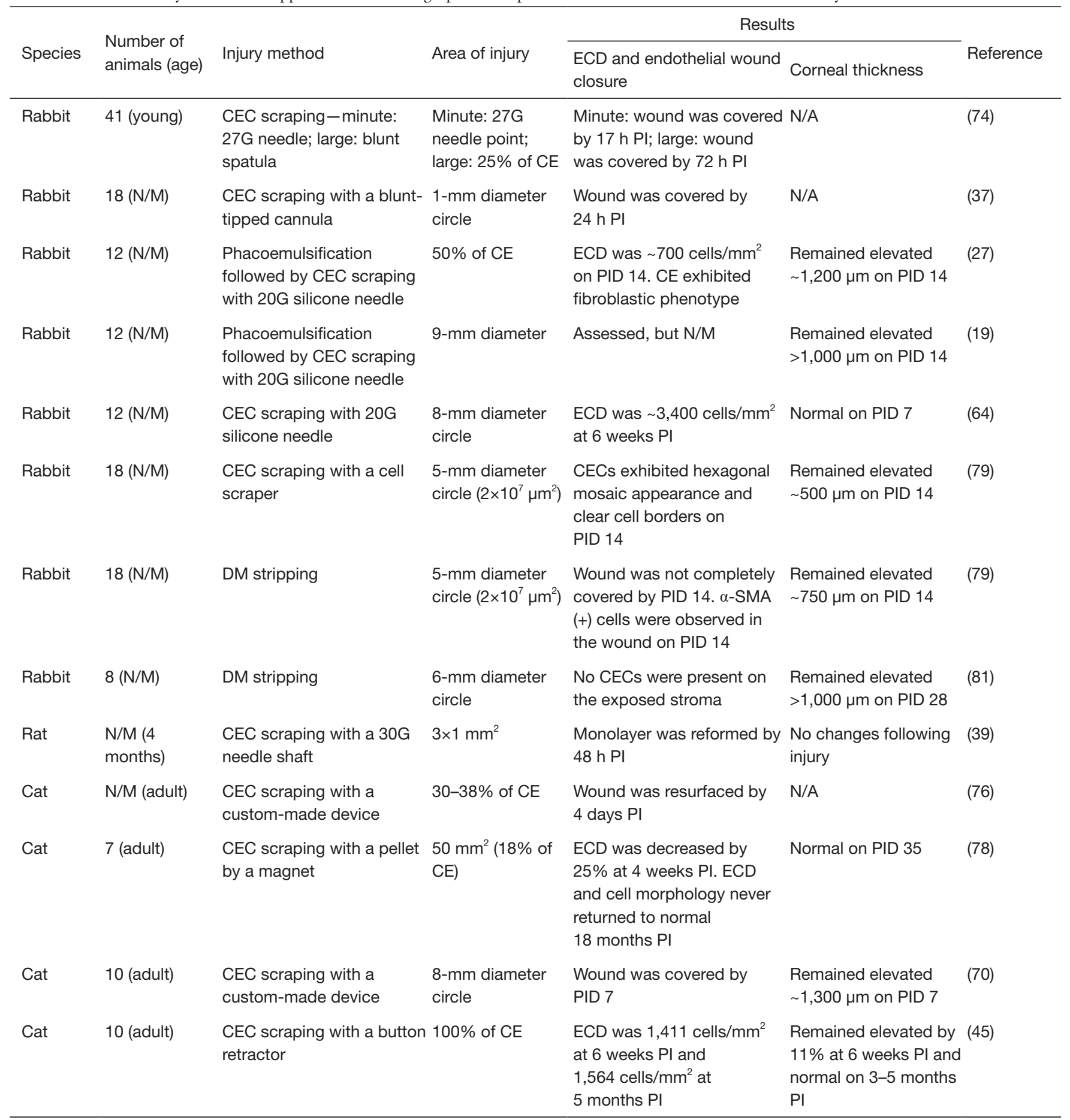

Table 2 (continued) 
Table 2 (continued)

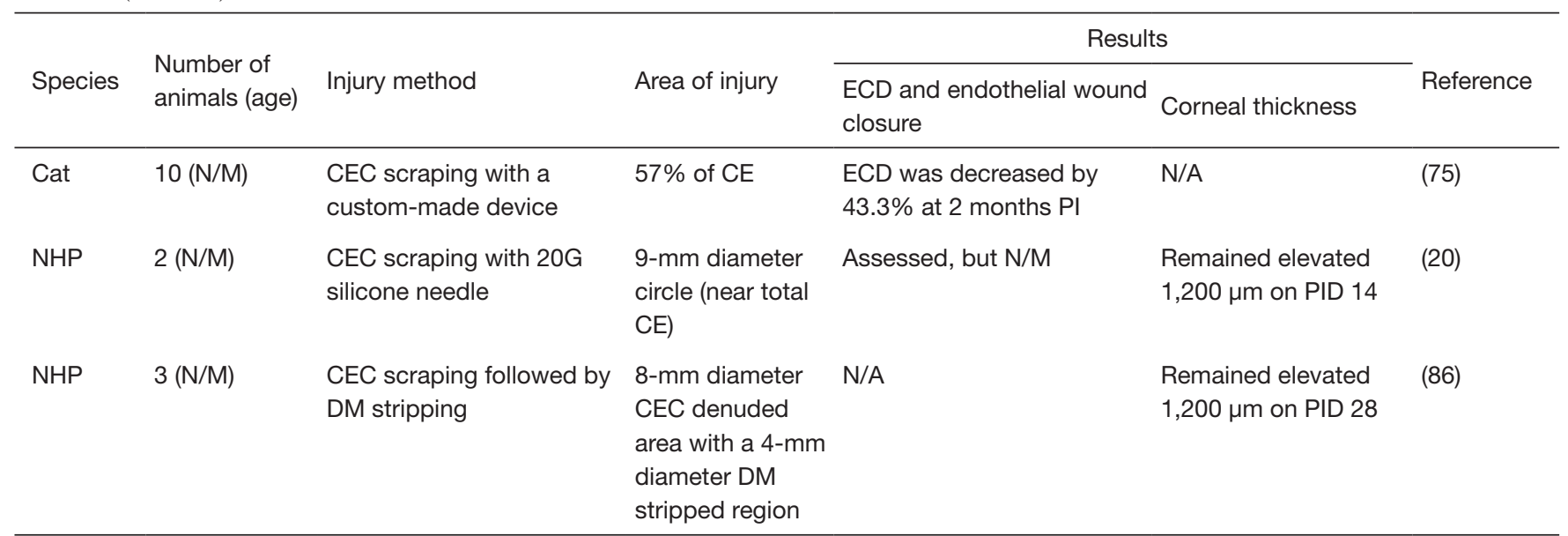

CE, corneal endothelium; CEC, corneal endothelial cells; ECD, endothelial cell density; N/A, not assessed; NHP, nonhuman primate; N/M, not mentioned; PI, post injury; PID, post-injury day.

CEC wound healing is more delayed with DM stripping compared to simple CEC scraping.

\section{Chemical injury}

Chemical injury methodology was originally devised in 1977 for corneal transplant experiments in animals in order to remove all of host cells and to induce longer-lasting corneal edema versus mechanical and cryoinjury without provoking corneal neovascularization (89). The key to success for this method is to irrigate the anterior chamber with physiological saline for a few seconds after injection of a chemical agent to minimize collateral tissue damage and subsequent complications including anterior uveitis, secondary glaucoma, and corneal neovascularization $(89,90)$.

Although various pharmacologic agents including povidone iodine, sodium hydroxide $(\mathrm{NaOH})$, and benzalkonium chloride (BAK) have been introduced into the anterior chamber to produce CEC cytotoxicity, BAK is the most commonly used agent for inducing bullous keratopathy in experimental animals. There is a doseresponse relationship with more extensive CEC damage occurring at higher BAK concentrations (91). In dose escalation studies in rabbits, at least $0.05 \% \mathrm{BAK}$ was needed to cause significant CEC damage ex vivo (91) and to increase corneal thickness at $24 \mathrm{~h}$ in vivo (90). The $0.05 \%$ BAK has also been utilized in mice and rats (92-95).

There has been cumulative evidence supporting that the population of corneal endothelial progenitor cells reside in the transitional zone between the peripheral cornea and trabecular meshwork $(14,16,96)$. It is thus expected that chemical injury by intracameral injection induces more extensive CEC damage versus the cryoinjury or mechanical debridement $(85,89,91)$. Even with this method of injury, however, some CEC regeneration, albeit incompletely, still follows. For example, resolution of corneal edema from the periphery to the central cornea with a decrease in corneal thickness and increase in CEC density were observed over time during a 14-day study period in rabbits following intracameral injection of $0.05 \mathrm{~N} \mathrm{NaOH}$ (97). The origin of these endothelial progenitors is poorly understood; however, Yam and colleagues speculated that alteration or disruption of the transitional zone could induce these cells to activate or proliferate in response to injury (15). This conclusion was based on observations that abnormal monolayer sheets of transitional zone endothelial cells formed and covered the surgical site following laser trabeculoplasty in human patients (98).

\section{Laser injury}

The Neodymium-doped yttrium aluminum garnet $(\mathrm{Nd}$ : YAG) laser uses photodisruption to cause microexplosions in tissue (99) and permits clinicians to treat intraocular tissues without entering the anterior chamber $(85,99,100)$. It is widely used for peripheral iridotomy and capsulotomy to treat acute angle closure glaucoma and posterior capsular opacification after cataract surgery, respectively $(85,99)$. Although these procedures are relatively safe with minimal complications including corneal ulcer and uveitis (85), the 
effects of Nd:YAG laser on CEC density vary and focal or generalized corneal decompensation can develop requiring a keratoplasty procedure in some patients (101).

Researchers have utilized a Nd:YAG laser on the corneal endothelium to study CEC repair $(35,85)$. Nash and colleagues observed that laser injury differs from other types of endothelial injury in that the healing response is significantly delayed (102). While mechanical or cryoinjury involving up to $50 \%$ of the total corneal endothelial surface caused formation of a complete monolayer in 2-5 days in rabbits $(35,36,57,74)$, endothelial lesions persisted at least 3 weeks after Nd:YAG laser injury (35). Some have speculated that the speed of endothelial migration could be slowed down once CECs reach the lasered DM and cell division could be inhibited due to laser-induced direct marginal cellular damage $(35,85)$. With regard to the recovery of physiological function of CECs, corneal thickness remained elevated 4 weeks after laser injury in rabbits (85). Studies where longer-term disruption of endothelial function is needed with minimal intraocular complications could benefit from this type of injury.

\section{UV irradiation}

CECs are especially susceptible to oxidative stress due to their lifelong exposure to light including UV radiation and high oxygen demand from active pump function (103). Indeed, corneas of patients with FECD exhibit accumulation of reactive oxygen species (ROS) and reactive nitrogen species (RNS), and elevated oxidative DNA damage in comparison to normal controls $(103,104)$. To mimic a prooxidative environment leading to mitochondrial and nuclear DNA damage and resultant corneal endothelial dysfunction, UV irradiation has been applied to the corneas of animals.

In general, the severity of UV-induced tissue damage depends on the wavelength, the intensity of the light, and the absorption spectrum of each tissue (105). Depending on the wavelength, UV light is classified into UVA (315-400 nm), UVB (280-315 nm) and UVC $(100-280 \mathrm{~nm})$. While UVC is almost exclusively filtered by ozone of the atmosphere, the terrestrial environment is constantly exposed to UVA and UVB radiation with the cornea absorbing $60-100 \%$ of UVB while UVA is primarily absorbed by the lens $(106,107)$. While UVAinduced oxidative stress is primarily mediated through the generation of ROS and RNS rather than direct DNA damage (108), UVB is directly absorbed by DNA bases in addition to ROS generation (108).
Similar to the cryoinjury model, experimental UV irradiation disrupts the corneal epithelium, which typically heals within one week (109). Variable anterior uveitis can develop following UV exposure, but usually regresses within $\sim 2$ days (110). Anterior uveitis was absent with wavelengths $>315 \mathrm{~nm}$ (110). Unlike cryoinjury which causes acute necrosis immediately after wounding, UV irradiation results in a slower onset of CEC damage (Figure 3). At the molecular level, UVA exposure induced a delayed damage in nuclear DNA with low CEC density in mice starting only at 1 month post-irradiation (109).

UVB irradiation induced CEC alterations in mice, rats, and rabbits with CEC apoptosis, less interdigitated cell borders, and corneal edema being observed $(31,111,112)$. UVB-induced CEC damage was accompanied with reduced concentrations of precursors of nicotinamide, a key metabolite in mitochondrial metabolism and antioxidant stress response. Subconjunctival injection of nicotinamide precursors effectively prevented UVB-induced CEC apoptosis in mice (31).

Liu and co-authors recently developed a nongenetic, UVA-induced late-onset FECD mouse model (109). UVA induced progressive CEC loss within 2 months postirradiation and furthermore, UVA caused formation of guttae-like lesions. Supplementation of $\mathrm{N}$-acetylcysteine, known for an antioxidant and ROS scavenger, increased CEC survival, suggesting that ROS quenching restored UVA-induced CEC loss. Interestingly, this murine model simulated female predisposition seen in FECD patients, with female mice showing an earlier onset of CEC loss and corneal edema at lower dose of UVA compared to male mice. They identified the involvement of CYP1B1, the estrogen-metabolizing enzyme, in sex-dependent differences in CEC susceptibility to UVA and also detected greater mitochondrial DNA damage and estrogen-DNA adduct formation in more severely affected female mice. Given the characteristics of UV irradiation including progressive CEC loss, simulating female predisposition, formation of guttaelike lesions, and mimicking environmental factors, this method may be the most physiologically relevant inducible animal model of FECD currently developed.

\section{Genetically modified animals}

Genetic studies have identified multiple gene mutations and loci associated with FECD. The major component of DM is collagen type VIII (COL8) and the alpha 1 and alpha 2 subunits of COL8 (COL8A1 and COL8A2) are equally and 
regularly organized within the anterior banded layer of DM in normal corneas (113). There are two clinical subtypes of FECD: an early-onset form and a late-onset form. The early-onset FECD is associated with missense mutations $\mathrm{Q} 455 \mathrm{~K}$ and $\mathrm{L} 450 \mathrm{~W}$ in the COL8A2 gene. Knock-in mouse models containing a point mutation homologous to the human Q455K and L450W COL8A2 mutation have been generated and possess endothelial phenotypes analogous to human FECD $(114,115)$. Both knock-in mouse models exhibited dilated endoplasmic reticulum (ER), suggesting that ER stress caused by the accumulation of misfolded proteins in the ER lumen and activation of unfolded protein response (UPR) resulted in FECD pathology $(114,115)$. Interestingly, L450W mutant mice showed better preservation of CECs and cell morphology clinically versus Q455K mutant mice but with a more severe vacuolization of CECs observed at an ultrastructural level in L450W versus Q455K mutant mice (115). It is speculated that dilated ER and large vacuoles in CECs of L450W mutant mice represent autophagy, a cellular pathway that occurs in response to ER stress in order to protect cells by degrading bulk protein aggregates, which may enhance CEC survival $(115,116)$. Induction of autophagy by lithium administration and reduction of oxidative and ER stress by $\mathrm{N}$-acetylcysteine administration were demonstrated to increase CEC survival in Q455K and L450W murine models, respectively $(116,117)$.

In comparison to early-onset FECD, the TCF4, TCF8, SLC4A11, LOXHD1 genes have been implicated in lateonset FECD (113). TCF4 and TCF8 genes encode the transcriptional factors E2-2 and ZEB1 respectively, both of which promote EnMT and suppress E-cadherin resulting in loss of cell-to-cell contact (118). Altered function of ZEB1 also contributes to abnormal ECM deposition by regulation of COL8A2 $(119,120)$. The intronic trinucleotide repeat expansion within the TCF 4 gene is responsible for about $70 \%$ of FECD cases $(121,122)$. The role of RNA toxicity in FECD pathology was confirmed that nuclear foci of expanded intronic repeats in TCF 4 in FECD-affected CECs sequesters RNA splicing factors leading to global mis-splicing of RNA $(123,124)$. Mutations in SLC4A11 and LOXHD1 cause cytoplasmic accumulation of proteins, which may be related to guttae formation through a mechanism involving ER stress and UPR (119).

SLC4A11 mutations account for $~ 5 \%$ of late-onset FECD patients as well as most cases of congenital hereditary endothelial dystrophy (CHED) $(121,125)$. The protein encoded by $S L C 4 A 11$ mediates $\mathrm{Na}^{+}: 2 \mathrm{~B}(\mathrm{OH})_{4}{ }^{-}$ cotransporter and was renamed $\mathrm{NaBC} 1(125,126)$. NaBC1 functions as a $\mathrm{Na}^{+}: \mathrm{OH}^{-}$permeable channel playing a critical role in sodium-mediated fluid transport in both the cornea and the kidney $(125,126)$. SLC4A11 knock-out mice demonstrate diffuse corneal edema, vacuolated CECs, and uniformly thickened DM histologically as observed in CHED patients and clinically showed progressive corneal edema and CEC damage with age $(122,125)$. These findings were attributed to accumulation of sodium chloride in the corneal stroma due to defective $\mathrm{NaBC} 1$ protein and altered water flux function of CECs (125).

In addition, the PPCD 1 mouse was characterized by abnormal growth of epithelialized CECs over the iridocorneal angle, posterior cornea, and iris and enlarged anterior chamber (127). The presence of CECs with epithelial phenotypes such as microvilli and inappropriate cytokeratin expression is a characteristic of the human autosomal dominant disorder posterior polymorphous corneal dystrophy (PPCD). COL8A2 mutations are also associated with PPCD in human patients $(113,127)$.

Finally, there is an intimate, bidirectional relationship between CECs and DM. Mechanotransduction is the process by which cells sense and relay extracellular signals of mechanical changes through transmembrane mechanoreceptors and actin cytoskeleton into the nucleus, controlling cell morphology and downstream signaling pathways (119). Yes-associated protein (YAP) encoded by the gene YAP1 and transcriptional coactivator with PDZbinding motif (TAZ) encoded by WWTR1 are major cellular mechanotransducers. YAP heterozygous $\left(\mathrm{Yap}^{+/}\right)$ mice had severe ocular abnormalities including an absent endothelium, and homozygous deletion of the Yap1 gene could not be studied due to embryonic lethality (128). By contrast, consequences of modification of TAZ expression are viable mice with a mostly normal ocular phenotype, permitting studies of corneal wound healing in vivo. Preliminary investigations of TAZ (Wwtr 1$)$ deficient mice demonstrate a lower CEC density with a softer DM in comparison to wild-type controls as well as reduced CEC proliferation following cryoinjury (129). Furthermore, FECD patients have a softer DM due to more widely spaced collagen fibrils in DM and CECs were displaced and distorted around the guttae in FECDaffected corneas $(130,131)$. Finally, the Q455K and L450W murine models demonstrated reduced DM stiffness prior to CEC loss, mimicking the mechanobiology seen in FECD 

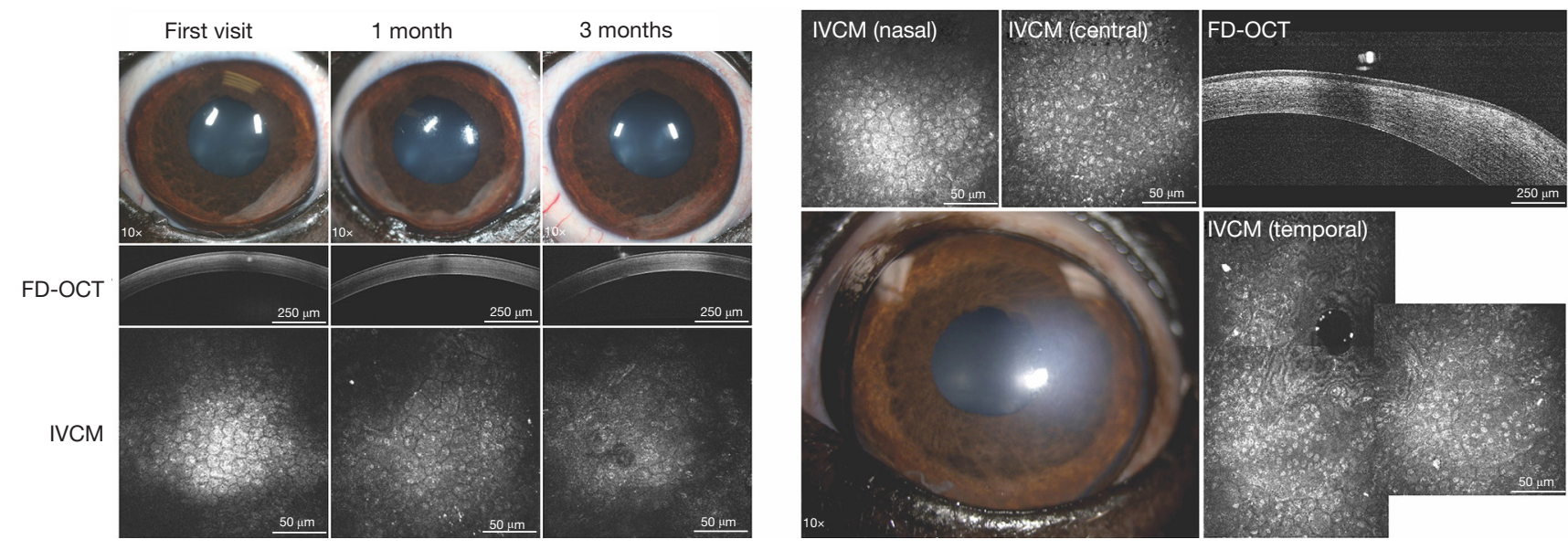

Figure 4 Anterior segment photography, FD-OCT and IVCM imaging of a 9-year-old male neutered Boston Terrier. (A) Right eye. The right cornea had a normal thickness and clarity for 3 months after the initial visit. However, IVCM showed progressive CEC damage of the central cornea including disrupted cell borders, pleomorphism, and polymegathism. (B) Left eye. Focal corneal edema was observed in the temporal paraxial cornea at the initial visit. With IVCM, mild pleomorphism and polymegathism was observed in the nasal cornea while marked pleomorphism and polymegathism with multinucleated giant cells and a guttae-like structure were found in the central and temporal cornea. CEC, corneal endothelial cell; FD-OCT, Fourier-domain optical coherence tomography; IVCM, in vivo confocal microscopy.

patients (131). Collectively, these observations suggest that mechanotransduction is critical in CEC health and disease and the interrelationship between DM and CECs is understudied (119).

\section{Spontaneous corneal endothelial dysfunction in animals}

A major advantage of using animals with naturally occurring diseases lies in their population diversity in comparison to the highly homogeneous background of laboratory animals, which could likely better reflect the complex genetic, environmental, and physiological variation identified in the human population (132). Spontaneous corneal endothelial decompensation has been identified in dogs, cats and mink (133-135). Corneal endothelial dystrophy (CED) in dogs is a bilateral, adult-onset, primary degeneration of CECs and is overrepresented in some specific canine breeds, suggesting an underlying presence of a heritable component like FECD in humans $(136,137)$. Clinically, polymegathism and pleomorphism of CECs are observed in CED-affected dogs, which increase in correlation with disease severity. Corneal edema, bullous keratopathy, and decreased vision are common consequences at later stages of disease similar to human patients $(136,137)$. Microscopically, thicker
DM and guttae-like deposits were identified in CEDaffected dogs versus age-matched control dogs $(134,137)$. In aggregate, these studies suggest that CED in dogs shares clinical and histological similarities with FECD in human patients.

When evaluating the efficacy of novel therapeutics, preclinical studies in laboratory animals are often poor predictors of human clinical trials due to strictly regulated husbandry environments as well as their highly inbred and uniform genetic background (132). For example, smoking, diabetes, and cardiovascular disease are environmental factors associated with the risk of FECD development (113). Therefore, utilizing client-owned dogs versus laboratory animals permit exposure to the same epigenetic factors as their human owners (136). Finally, advanced ocular imaging including OCT and IVCM can be employed in the longitudinal evaluation of veterinary patients (Figure 4). Therefore, veterinary clinical trials could serve as a bridge between preclinical and human clinical studies and facilitate rapid translation of novel drugs, devices, biomaterials, surgical procedures, or regenerative therapeutic strategies (132). The investigation of veterinary patients with spontaneous corneal endothelial dysfunction may improve the predictive value of interventions for treating human patients and has the value added attribute of 
improving vision care for veterinary patients in need.

Superficial keratectomy with conjunctival advancement hood flap (SKCAHF), thermokeratoplasty, and corneal collagen crosslinking procedures have been adapted by veterinary ophthalmologists from their physician-based colleagues as symptomatic therapy in client-owned dogs suffering from severe bullous keratopathy (138-140). EK is now being performed in dogs with endothelial dysfunction to improve visual function $(141,142)$. The relative largesize of canine eyes with similar corneal anatomy to humans could serve as an optimal platform to test and optimize new surgical techniques $(136,142)$. Finally, veterinary clinical trials involving topical application of ROCK inhibitor are currently in progress to stimulate CEC proliferation in dogs affected with early stage of CED (unpublished).

\section{Conclusions}

In this review, we have highlighted historical and recent key findings relevant to CEC regeneration and various animal models of inducing corneal endothelial dysfunction. Wide variations exist in the regenerative response to CEC injury depending on the species used, the nature of methods of CEC injury and specific genetic modifications, which likely contributes to differences in outcomes observed between promising animal studies and negative human clinical trials (143). In particular, the variable proliferative capacity of CEC of laboratory animals may make it difficult to interpret the data obtained or observe differences between treatment groups. Selecting aged animals, choosing a technique where endothelial cells are permanently destroyed (56), or utilizing a spontaneous model that better mimics the disease process of interest are all strategies for investigators to consider when selecting an appropriate animal model. Because preclinical studies are critical in the decision to pursue human clinical trials (144), researchers should choose appropriate animal models carefully and should optimize and standardize experimental protocols to facilitate the translation of research findings from animals to humans.

\section{Acknowledgments}

Funding: This study was funded by grants from the National Institutes of Health K08EY028199 (BCL), R01EY016134 (CJM, SMT and VR), the National Eye Institute core grant P30EY12576 and an unrestricted grant for corneal research from the Family of Claire Burns.

\section{Footnote}

Provenance and Peer Review: This article was commissioned by the Guest Editor (Susanna S Park) for the series "Novel Tools and Therapies for Ocular Regeneration" published in Annals of Translational Medicine. The article has undergone external peer review.

Conflicts of Interest: All authors have completed the ICMJE uniform disclosure form (available at https://dx.doi. org/10.21037/atm-20-4389). The series "Novel Tools and Therapies for Ocular Regeneration" was commissioned by the editorial office without any funding or sponsorship. CJM reports grants from National Eye Institute, and an unrestricted grant from the family of Claire Burns, during the conduct of the study. SMT reports grants from NEI, and an unrestricted grant from the family of Claire Burns, during the conduct of the study. The authors have no other conflicts of interest to declare.

Ethical Statement: The authors are accountable for all aspects of the work in ensuring that questions related to the accuracy or integrity of any part of the work are appropriately investigated and resolved.

Open Access Statement: This is an Open Access article distributed in accordance with the Creative Commons Attribution-NonCommercial-NoDerivs 4.0 International License (CC BY-NC-ND 4.0), which permits the noncommercial replication and distribution of the article with the strict proviso that no changes or edits are made and the original work is properly cited (including links to both the formal publication through the relevant DOI and the license). See: https://creativecommons.org/licenses/by-nc-nd/4.0/.

\section{References}

1. Tuft SJ, Coster DJ. The corneal endothelium. Eye (Lond) 1990;4:389-424.

2. Damala M, Singh V. Corneal regeneration: Therapy and surgery. In: Alio JL, Alio del Barrio JL, Arnalich-Montiel F. editors. Corneal Regeneration: Therapy and Surgery. Cham: Springer, 2019:13-22.

3. Koizumi N, Okumura N, Kinoshita S. Development of new therapeutic modalities for corneal endothelial disease focused on the proliferation of corneal endothelial cells using animal models. Exp Eye Res 2012;95:60-7.

4. Okumura N, Koizumi N. Regeneration of the Corneal 
Endothelium. Curr Eye Res 2020;45:303-12.

5. Alomar TS, Al-Aqaba M, Gray T, et al. Histological and confocal microscopy changes in chronic corneal edema: Implications for endothelial transplantation. Invest Ophthalmol Vis Sci 2011;52:8193-207.

6. Tong CM, Melles GRJ. Where is endothelial keratoplasty going: from Descemet stripping (automated) endothelial keratoplasty to Descemet membrane endothelial keratoplasty to Descemet membrane endothelial transfer? Can J Ophthalmol 2012;47:197-200.

7. Garcerant D, Hirnschall N, Toalster N, et al. Descemet's stripping without endothelial keratoplasty. Curr Opin Ophthalmol 2019;30:275-85.

8. Van den Bogerd B, Dhubhghaill SN, Koppen C, et al. A review of the evidence for in vivo corneal endothelial regeneration. Surv Ophthalmol 2018;63:149-65.

9. Shah RD, Randleman JB, Grossniklaus HE. Spontaneous corneal clearing after Descemet's stripping without endothelial replacement. Ophthalmology 2012;119:256-60.

10. Borkar DS, Veldman P, Colby KA. Treatment of fuchs endothelial dystrophy by descemet stripping without endothelial keratoplasty. Cornea 2016;35:1267-73.

11. Treffers WF. Human Corneal Endothelial Wound Repair: In Vitro and In Vivo. Ophthalmology 1982;89:605-13.

12. Zagórski Z. Replication Capacity of the Regenerating Human Corneal Endothelium in Organ Culture. In: Goh Naumann, Gloor BP. editors. Wundheilung des Auges und ihre Komplikationen. Munich: JF Bergmann Verlag, 1980:223-5.

13. Simonsen AH, Sørensen KE, Sperling S. Thymidine incorporation by human corneal endothelium during organ culture. Acta Ophthalmol (Copenh) 1981;59:110-8.

14. McGowan SL, Edelhauser HF, Pfister RR, et al. Stem cell markers in the human posterior limbus and corneal endothelium of unwounded and wounded corneas. Mol Vis 2007;13:1984-2000.

15. Yam GH, Seah X, Yusoff NZBM, et al. Characterization of Human Transition Zone Reveals a Putative ProgenitorEnriched Niche of Corneal Endothelium. Cells 2019;8:1244.

16. He Z, Campolmi N, Gain P, et al. Revisited microanatomy of the corneal endothelial periphery: New evidence for continuous centripetal migration of endothelial cells in humans. Stem Cells 2012;30:2523-34.

17. Liu Y, Sun H, Hu M, et al. Human corneal endothelial cells expanded in vitro are a powerful resource for tissue engineering. Int J Med Sci 2017;14:128-35.
18. Okumura N, Ueno M, Koizumi N, et al. Enhancement on primate corneal endothelial cell survival in vitro by a rock inhibitor. Invest Ophthalmol Vis Sci 2009;50:3680-7.

19. Okumura N, Koizumi N, Ueno M, et al. ROCK inhibitor converts corneal endothelial cells into a phenotype capable of regenerating in vivo endothelial tissue. Am J Pathol 2012;181:268-77.

20. Okumura N, Sakamoto Y, Fujii K, et al. Rho kinase inhibitor enables cell-based therapy for corneal endothelial dysfunction. Sci Rep 2016;6:26113.

21. Meekins LC, Rosado-Adames N, Maddala R, et al. Corneal endothelial cell migration and proliferation enhanced by rho kinase (ROCK) inhibitors in in vitro and in vivo models. Invest Ophthalmol Vis Sci 2016;57:6731-8.

22. Okumura N, Koizumi N, Kay EDP, et al. The ROCK inhibitor eye drop accelerates corneal endothelium wound healing. Invest Ophthalmol Vis Sci 2013;54:2493-502.

23. Kinoshita S, Koizumi N, Ueno M, et al. Injection of cultured cells with a ROCK inhibitor for bullous keratopathy. N Engl J Med 2018;378:995-1003.

24. Okumura N, Koizumi N, Ueno M, et al. Enhancement of corneal endothelium wound healing by Rho-associated kinase (ROCK) inhibitor eye drops. Br J Ophthalmol 2011;95:1006-9.

25. Macsai MS, Shiloach M. Use of Topical Rho Kinase Inhibitors in the Treatment of Fuchs Dystrophy after Descemet Stripping Only. Cornea 2019;38:529-34.

26. Koizumi N, Okumura N, Ueno M, et al. Rho-associated kinase inhibitor eye drop treatment as a possible medical treatment for fuchs corneal dystrophy. Cornea 2013;32:1167-70.

27. Okumura N, Okazaki Y, Inoue R, et al. Effect of the rhoassociated kinase inhibitor eye drop (Ripasudil) on corneal endothelial wound healing. Invest Ophthalmol Vis Sci 2016;57:1284-92.

28. Roy O, Leclerc VB, Bourget JM, et al. Understanding the process of corneal endothelial morphological change in vitro. Invest Ophthalmol Vis Sci 2015;56:1228-37.

29. Lee J, Jung E, Heur M. Injury induces endothelial to mesenchymal transition in the mouse corneal endothelium in vivo via FGF2. Mol Vis 2019;25:22-34.

30. Li Z, Duan H, Li W, et al. Nicotinamide inhibits corneal endothelial mesenchymal transition and accelerates wound healing. Exp Eye Res 2019;184:227-33.

31. Zhao C, Li W, Duan H, et al. NAD+ precursors protect corneal endothelial cells from UVB-induced apoptosis. Am J Physiol Cell Physiol 2020;318:C796-805.

32. Zhu C, Joyce NC. Proliferative response of corneal 
endothelial cells from young and older donors. Invest Ophthalmol Vis Sci 2004;45:1743-51.

33. Joyce NC, Harris DL, Mello DM. Mechanisms of mitotic inhibition in corneal endothelium: Contact inhibition and TGF- 2. Invest Ophthalmol Vis Sci 2002;43:2152-9.

34. Joyce NC, Zhu CC, Harris DL. Relationship among oxidative stress, dna damage, and proliferative capacity in human corneal endothelium. Invest Ophthalmol Vis Sci 2009;50:2116-22.

35. Schubert HD, Trokel S. Endothelial repair following $\mathrm{Nd}$ :YAG laser injury. Invest Ophthalmol Vis Sci 1984;25:971-6.

36. Silverstein AM, Khodadoust AA, Prendergast RA. Desquamation of corneal endothelial cells. Invest Ophthalmol Vis Sci 1982;22:351-8.

37. Ichijima H, Petroll WM, Barry PA, et al. Actin filament organization during endothelial wound healing in the rabbit cornea: Comparison between transcorneal freeze and mechanical scrape injuries. Invest Ophthalmol Vis Sci 1993;34:2803-12.

38. Rolev K, Coussons P, King L, et al. Experimental models of corneal endothelial cell therapy and translational challenges to clinical practice. Exp Eye Res 2019;188:107794.

39. Tuft SJ, Williams KA, Coster DJ. Endothelial repair in the rat cornea. Invest Ophthalmol Vis Sci 1986;27:1199-204.

40. Van Horn DL, Sendele DD, Seideman S, et al. Regenerative capacity of the corneal endothelium in rabbit and cat. Invest Ophthalmol Vis Sci 1977;16:597-613.

41. Mills NL, Donn A. Incorporation of tritium-labeled thymidine by rabbit corneal endothelium. Arch Ophthalmol 1960;64:443-6.

42. Matsubara M, Tanishima T. Wound-healing of corneal endothelium in monkey: an autoradiographic study. Jpn J Ophthalmol 1983;27:444-50.

43. Befanis PJ, Peiffer RL, Brown D. Endothelial repair of the canine cornea. Am J Vet Res 1981;42:590-5.

44. Van Horn DL, Hyndiuk RA. Endothelial wound repair in primate cornea. Exp Eye Res 1975;21:113-24.

45. Huang PT, Nelson LR, Bourne WM. The morphology and function of healing cat corneal endothelium. Invest Ophthalmol Vis Sci 1989;30:1794-801.

46. Miyagi H, Kim S, Li J, et al. Topical rho-associated kinase inhibitor, Y27632, accelerates corneal endothelial regeneration in a canine cryoinjury model. Cornea 2019;38:352-9.

47. Bostan C, Thériault M, Forget KJ, et al. In vivo functionality of a corneal endothelium transplanted by cell-injection therapy in a feline model. Invest Ophthalmol Vis Sci 2016;57:1620-34.

48. Morita H. Specular microscopy of corneal endothelial cells in rabbits. J Vet Med Sci 1995;57:273-7.

49. Doughty MJ. The cornea and corneal endothelium in the aged rabbit. Optom Vis Sci 1994;71:809-18.

50. Valdez-Garcia JE, Lozano-Ramirez JF, Zavala J. Adult white New Zealand rabbit as suitable model for corneal endothelial engineering. BMC Res Notes 2015;8:28.

51. Maumenee AE, Kornblueth W. Regeneration of the corneal stromal cells. I. Technique for destruction of corneal corpuscles by application of solidified (frozen) carbon dioxide. Am J Ophthalmol 1948;31:699-702.

52. Han SB, Ang H, Balehosur D, et al. A mouse model of corneal endothelial decompensation using cryoinjury. Mol Vis 2013;19:1222-30.

53. Khodadoust AA, Green K. Physiological function of regenerating endothelium. Invest Ophthalmol 1976;15:96-101.

54. Minkowski JS, Bartels SP, Delori FC, et al. Corneal endothelial function and structure following cryo-injury in the rabbit. Invest Ophthalmol Vis Sci 1984;25:1416-25.

55. Ichijima H, Petroll WM, Jester JV, et al. In Vivo confocal microscopic studies of endothelial wound healing in rabbit cornea. Cornea 1993;12:369-78.

56. Mimura T, Yamagami S, Usui T, et al. Long-term outcome of iron-endocytosing cultured corneal endothelial cell transplantation with magnetic attraction. Exp Eye Res 2005;80:149-57.

57. Chi HH, Kelman CD. Effects of freezing on ocular tissues. I. Clinical and histologic study of corneal endothelium. Am J Ophthalmol 1966;61:630-41.

58. Oh JY, Lee HJ, Khwarg SI, et al. Corneal cell viability and structure after transcorneal freezing - thawing in the human cornea. Clin Ophthalmol 2010;4:477-80.

59. Thomasy SM, Eaton JS, Timberlake MJ, et al. Species differences in the geometry of the anterior segment differentially affect anterior chamber cell scoring systems in laboratory animals. J Ocul Pharmacol Ther 2016;32:28-37.

60. Staatz WD, Van Horn DL. The effects of aging and inflammation on corneal endothelial wound healing in rabbits. Invest Ophthalmol Vis Sci 1980;19:983-6.

61. Petroll WM, Jester JV, Bean JJ, et al. Myofibroblast transformation of cat corneal endothelium by transforming growth factor- $\beta 1,-\beta 2$, and $-\beta 3$. Invest Ophthalmol Vis Sci 1998;39:2018-32.

62. Petroll WM, Barry-Lane PA, Cavanagh HD, et al. ZO-1 
reorganization and myofibroblast transformation of corneal endothelial cells after freeze injury in the cat. Exp Eye Res 1997;64:257-67.

63. Lee JG, Kay EDP. FGF-2-mediated signal transduction during endothelial mesenchymal transformation in corneal endothelial cells. Exp Eye Res 2006;83:1309-16.

64. Yamashita K, Hatou S, Inagaki E, et al. A Rabbit Corneal Endothelial Dysfunction Model Using EndothelialMesenchymal Transformed Cells. Sci Rep 2018;8:16868.

65. Eaton JS, Miller PE, Bentley E, et al. The SPOTS System: An Ocular Scoring System Optimized for Use in Modern Preclinical Drug Development and Toxicology. J Ocul Pharmacol Ther 2017;33:718-34.

66. Yamada J, Ueno M, Toda M, et al. Allogeneic Sensitization and Tolerance Induction After Corneal Endothelial Cell Transplantation in Mice. Invest Ophthalmol Vis Sci 2016:57:4572-80.

67. Chang YK, Hwang JS, Chung TY, et al. SOX2 Activation Using CRISPR / dCas9 Promotes Wound Healing in Corneal Endothelial Cells. Stem Cells 2018;36:1851-62.

68. Kim JA, Ko JH, Ko AY, et al. TSG-6 Protects Corneal Endothelium From Transcorneal Cryoinjury in Rabbits. Invest Ophthalmol Vis Sci 2014;55:4905-12.

69. Mimura T, Yamagami S, Usui T, et al. Necessary prone position time for human corneal endothelial precursor transplantation in a rabbit endothelial deficiency model. Curr Eye Res 2007;32:617-23.

70. Solomon A, Solberg Y, Belkin M, et al. Effect of corticosteroids on healing of the corneal endothelium in cats. Graefes Arch Clin Exp Ophthalmol 1997;235:325-9.

71. Morton PL, Ormsby HL, Basu PK. Healing of endothelium and Descemet's membrane of rabbit cornea. Am J Ophthalmol 1958;46:62-7.

72. Honda H, Ogita Y, Higuchi S, et al. Cell movements in a living mammalian tissue: Long-term observation of individual cells in wounded corneal endothelia of cats. J Morphol 1982;174:25-39.

73. Maurice DM, Giardini AA. Swelling of the cornea in vivo after the destruction of its limiting layers. Br J Ophthalmol 1951;35:791-7.

74. Chi HH, Teng CC, Katzin HM. Healing process in the mechanical denudation of the corneal endothelium. Am J Ophthalmol 1960;49:693-703.

75. Landshman N, Ben-hanan I, Ben-chaim O, et al. A model of corneal re-endothelialization after surgical trauma. Curr Eye Res 1985;4:555-61.

76. Landshman N, Solomon A, Belkin M. Cell Division in the Healing of the Corneal Endothelium of Cats. Arch
Ophthalmol 1989;107:1804-8.

77. Cogan DG. A new method for studying endothelial regeneration. Ophthalmologica 1949;118:440-3.

78. Ling TL, Vannas A, Holden BA. Long-term changes in corneal endothelial morphology following wounding in the cat. Invest Ophthalmol Vis Sci 1988;29:1407-12.

79. Chen J, Li Z, Zhang L, et al. Descemet's Membrane Supports Corneal Endothelial Cell Regeneration in Rabbits. Sci Rep 2017;7:6983.

80. Melles GRJ, Wijdh RHJ, Nieuwendaal CP. A Technique to Excise the Descemet Membrane from a Recipient Cornea (Descemetorhexis). Cornea 2004;23:286-8.

81. Mimura T, Yamagami S, Yokoo S, et al. Cultured human corneal endothelial cell transplantation with a collagen sheet in a rabbit model. Invest Ophthalmol Vis Sci 2004;45:2992-7.

82. Honda N, Mimura T, Usui T, et al. Descemet stripping automated endothelial keratoplasty using cultured corneal endothelial cells in a rabbit model. Arch Ophthalmol 2009;127:1321-6.

83. Ishino Y, Sano Y, Nakamura T, et al. Amniotic membrane as a carrier for cultivated human corneal endothelial cell transplantation. Invest Ophthalmol Vis Sci 2004;45:800-6.

84. Kim K, Sim BR, Khang G. Nature-Derived Aloe Vera Gel Blended Silk Fibroin Film Scaffolds for Cornea Endothelial Cell Regeneration and Transplantation. ACS Appl Mater Interfaces 2016;8:15160-8.

85. Zhang W, Hu Y, Lu L, et al. Rabbit Model of Corneal Endothelial Injury Established Using the Nd:YAG Laser. Cornea 2017;36:1274-81.

86. Kimoto M, Shima N, Yamaguchi M, et al. Development of a bioengineered corneal endothelial cell sheet to fit the corneal curvature. Invest Ophthalmol Vis Sci 2014;55:2337-43.

87. Mehta JS, Peh GSL, Rizwan M, et al. Evaluation of corneal endothelial cell monolayer formation on synthetic guttata micro-structures to study the feasibility of corneal endothelial cell regenerative therapy. Invest Ophthalmol Vis Sci 2016;57:5282.

88. Okumura N, Matsumoto D, Fukui Y, et al. Feasibility of cell-based therapy combined with descemetorhexis for treating Fuchs endothelial corneal dystrophy in rabbit model. PLoS One 2018;13:e0191306.

89. Maurice D, Perlman M. Permanent destruction of the corneal endothelium in rabbits. Invest Ophthalmol Vis Sci 1977;16:646-9.

90. Britton B, Hervey R, Kasten K, et al. Intraocular irritation evaluation of benzalkonium chloride in rabbits. 
Ophthalmic Surg 1976;7:46-55.

91. Segarra S, Leiva M, Costa D, et al. A dose-escalation ex vivo study on the effects of intracameral benzalkonium chloride in,. BMC Vet Res 2018;14:39.

92. Hayashi T, Yamagami S, Tanaka K, et al. A Mouse Model of Allogeneic Corneal Endothelial Cell Transplantation. Cornea 2008;27:699-705.

93. Bredow L, Schwartzkopff J, Reinhard T. Regeneration of corneal endothelial cells following keratoplasty in rats with bullous keratopathy. Mol Vis 2014;20:683-90.

94. Hayashi T, Yamagami S, Tanaka K, et al. Immunologic mechanisms of corneal allografts reconstituted from cultured allogeneic endothelial cells in an immuneprivileged site. Invest Ophthalmol Vis Sci 2009;50:3151-8.

95. Ang M, Konstantopoulos A, Goh G, et al. Evaluation of a Micro-Optical Coherence Tomography for the Corneal Endothelium in an Animal Model. Sci Rep 2016;6:29769.

96. Whikehart DR, Parikh CH, Vaughn A V., et al. Evidence suggesting the existence of stem cells for the human corneal endothelium. Mol Vis 2005;11:816-24.

97. Choi SO, Jeon HS, Hyon JY, et al. Recovery of corneal endothelial cells from periphery after injury. PLoS One 2015;10:e0138076.

98. Alexander RA, Grierson I. Morphological effects of argon laser trabeculoplasty upon the glaucomatous human meshwork. Eye 1989;3:719-26.

99. Seitz Berthold; Langenbucher Achim. Lasers in ophthalmology. Lancet 2000;356:S26-8.

100.Dragnea DC, Ní Dhubhghaill S, Bourgonje VJA, et al. In Vitro Evaluation of the Feasibility of Slit-Lamp Nd: YAG Laser Descemetorhexis. Cornea 2020;39:229-33.

101. Wang PX, Koh VTC, Loon SC. Laser iridotomy and the corneal endothelium: A systemic review. Acta Ophthalmol 2014;92:604-16.

102. Nash JP, Wickham MG, Binder PS. Corneal damage following focal laser intervention. Exp Eye Res 1978;26:641-50.

103.Jurkunas UV, Bitar MS, Funaki T, et al. Evidence of oxidative stress in the pathogenesis of fuchs endothelial corneal dystrophy. Am J Pathol 2010;177:2278-89.

104. Buddi R, Lin B, Atilano SR, et al. Evidence of oxidative stress in human corneal diseases. J Histochem Cytochem 2002;50:341-51.

105.Ivanov I V, Mappes T, Schaupp P, et al. Ultraviolet radiation oxidative stress affects eye health. J Biophotonics 2018;11:e201700377.

106.Ibrahim OMA, Kojima T, Wakamatsu TH, et al. Corneal and retinal effects of ultraviolet-B exposure in a soft contact lens mouse model. Invest Ophthalmol Vis Sci 2012;53:2403-13.

107. Wojcik KA, Kaminska A, Blasiak J, et al. Oxidative stress in the pathogenesis of keratoconus and Fuchs endothelial corneal dystrophy. Int J Mol Sci 2013;14:19294-308.

108. Birch-Machin MA, Swalwell H. How mitochondria record the effects of UV exposure and oxidative stress using human skin as a model tissue. Mutagenesis 2010;25:101-7.

109. Liu C, Miyajima T, Melangath G, et al. Ultraviolet A light induces DNA damage and estrogen-DNA adducts in Fuchs endothelial corneal dystrophy causing females to be more affected. Proc Natl Acad Sci U S A 2020;117:573-83.

110.Pitts DG, Cullen AP, Hacker PD. Ocular effects of ultraviolet radiation from 295 to $365 \mathrm{~nm}$. Invest Ophthalmol Vis Sci 1977;16:932-9.

111. Riley MV, Susan S, Peters MI, et al. The effects of UV-b irradiation on the corneal endothelium. Curr Eye Res 1987;6:1021-33.

112. Kronschläger M, Talebizadeh N, Yu Z, et al. Apoptosis in Rat Cornea after in Vivo Exposure to Ultraviolet Radiation at $300 \mathrm{~nm}$. Cornea 2015;34:945-9.

113. Vedana G, Villarreal G, Jun AS. Fuchs endothelial corneal dystrophy: Current perspectives. Clin Ophthalmol 2016;10:321-30.

114.Jun AS, Meng H, Ramanan N, et al. An alpha 2 collagen VIII transgenic knock-in mouse model of Fuchs endothelial corneal dystrophy shows early endothelial cell unfolded protein response and apoptosis. Hum Mol Genet 2012;21:384-93.

115.Meng H, Matthaei M, Ramanan N, et al. L450W and Q455K Col8a2 knock-in mouse models of fuchs endothelial corneal dystrophy show distinct phenotypes and evidence for altered autophagy. Invest Ophthalmol Vis Sci 2013;54:1887-97.

116. Kim EC, Meng H, Jun AS. Lithium treatment increases endothelial cell survival and autophagy in a mouse model of Fuchs endothelial corneal dystrophy. Br J Ophthalmol 2013;97:1068-73.

117.Kim EC, Meng H, Jun AS. N-Acetylcysteine increases corneal endothelial cell survival in a mouse model of Fuchs endothelial corneal dystrophy. Exp Eye Res 2014;127:20-5.

118. Baratz KH, Tosakulwong N, Ryu E, et al. E2-2 protein and Fuchs's corneal dystrophy. N Engl J Med 2010;363:1016-24.

119.Ali M, Raghunathan V, Li JY, et al. Biomechanical relationships between the corneal endothelium and Descemet's membrane. Exp Eye Res 2016;152:57-70. 


\section{Page 18 of 18}

120.Wieben ED, Aleff RA, Eckloff BW, et al. Comprehensive assessment of genetic variants within TCF4 in Fuchs' endothelial corneal dystrophy. Invest Ophthalmol Vis Sci 2014;55:6101-7.

121. Malhotra D, Loganathan SK, Chiu AM, et al. Human Corneal Expression of SLC4A11, a Gene Mutated in Endothelial Corneal Dystrophies. Sci Rep 2019;9:9681.

122.Zhang J, McGhee CNJ, Patel DV. The Molecular Basis of Fuchs' Endothelial Corneal Dystrophy. Mol Diagn Ther 2019;23:97-112.

123.Du J, Aleff RA, Soragni E, et al. RNA toxicity and missplicing in the common eye disease fuchs endothelial corneal dystrophy. J Biol Chem 2015;290:5979-90.

124. Wieben ED, Aleff RA, Tang X, et al. Trinucleotide repeat expansion in the transcription factor 4 (TCF4) gene leads to widespread mrna splicing changes in fuchs' endothelial corneal dystrophy. Invest Ophthalmol Vis Sci 2017;58:343-52.

125.Han SB, Ang HP, Poh R, et al. Mice with a targeted disruption of Slc4a11 model the progressive corneal changes of congenital hereditary endothelial dystrophy. Invest Ophthalmol Vis Sci 2013;54:6179-89.

126.Jalimarada SS, Ogando DG, Vithana EN, et al. Ion transport function of SLC4A11 in corneal endothelium. Invest Ophthalmol Vis Sci 2013;54:4330-40.

127. Shen AL, O'Leary KA, Dubielzig RR, et al. The PPCD1 mouse: Characterization of a mouse model for posterior polymorphous corneal dystrophy and identification of a candidate gene. PLoS One 2010;5:e12213.

128. Kim S, Thomasy SM, Raghunathan VK, et al. Ocular phenotypic consequences of a single copy deletion of the Yap1 gene (Yap1+/-) in mice. Mol Vis 2019;25:129-42.

129.Leonard BC, Kim S, Jalilian I, et al. TAZ (Wwtr1) deficiency: A murine model of late-onset Fuchs endothelial corneal dystrophy. Invest Ophthalmol Vis Sci 2019;60:2170.

130.Xia D, Zhang S, Nielsen E, et al. The Ultrastructures and Mechanical Properties of the Descement's Membrane in Fuchs Endothelial Corneal Dystrophy. Sci Rep 2016;6:23096.

131.Leonard BC, Jalilian I, Raghunathan VK, et al. Biomechanical changes to Descemet's membrane precede endothelial cell loss in an early-onset murine model of Fuchs endothelial corneal dystrophy. Exp Eye Res 2019;180:18-22.

132. Kol A, Arzi B, Athanasiou KA, et al. Companion animals: Translational scientist's new best friends. Sci Transl Med 2015;7:308ps21.

133. Hadlow WJ. Chronic Corneal Edema in Aged Ranch Mink. Vet Pathol 1987;24:323-9.

134. Martin CL, Dice PF. Corneal endothelial dystrophy in the

\section{Park et al. Animal models of corneal endothelial dysfunction}

dog. J Am Anim Hosp Assoc 1982;18:327-36.

135. Bistner SI, Aguirre G, Shively JN. Hereditary corneal dystrophy in the Manx cat: a preliminary report. Invest Ophthalmol 1976;15:15-26.

136. Thomasy SM, Cortes DE, Hoehn AL, et al. In vivo imaging of corneal endothelial dystrophy in boston terriers: A spontaneous, canine model for fuchs'endothelial corneal dystrophy. Invest Ophthalmol Vis Sci 2016;57:OCT495-503.

137.Shull OR, Reilly CM, Davis LB, et al. Phenotypic characterization of corneal endothelial dystrophy in German shorthaired and wirehaired pointers using in vivo advanced corneal imaging and histopathology. Cornea 2018;37:88-94.

138. Horikawa T, Thomasy S, Stanley A, et al. Superficial Keratectomy and Conjunctival Advancement Hood Flap (SKCAHF) for the Management of Bullous Keratopathy: Validation in Dogs With Spontaneous Disease. Cornea 2016;35:1295-304.

139. Michau TM, Gilger BC, Maggio F, et al. Use of thermokeratoplasty for treatment of ulcerative keratitis and bullous keratopathy secondary to corneal endothelial disease in dogs: 13 Cases (1994-2001). J Am Vet Med Assoc 2003;222:607-12.

140. Kim J, Ji DB, Takiyama N, et al. Corneal collagen crosslinking following superficial keratectomy as treatment for corneal endothelial cell dystrophy in dogs: Preliminary clinical study. Vet Ophthalmol 2019;22:440-7.

141.Boo G, Whittaker CJG, Caruso KA, et al. Early postoperative results of Descemet's stripping endothelial keratoplasty in six dogs with corneal endothelial dystrophy. Vet Ophthalmol 2019;22:879-90.

142. Armour MD, Askew TE, Eghrari AO. Endothelial keratoplasty for corneal endothelial dystrophy in a dog. Vet Ophthalmol 2019;22:545-51.

143. Bracken MB. Why animal studies are often poor predictors of human reactions to exposure. J R Soc Med 2009;102:120-2.

144.Perel P, Roberts I, Sena E, et al. Comparison of treatment effects between animal experiments and clinical trials: Systematic review. BMJ 2007;334:197-200.

Cite this article as: Park S, Leonard BC, Raghunathan VK, Kim S, Li JY, Mannis MJ, Murphy CJ, Thomasy SM. Animal models of corneal endothelial dysfunction to facilitate development of novel therapies. Ann Transl Med 2021;9(15):1271. doi: $10.21037 / \mathrm{atm}-20-4389$ 